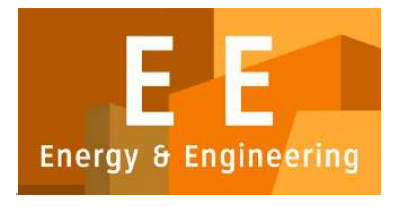

PAPER - OPEN ACCESS

\title{
Pengaruh Sosial Budaya Terhadap Perencanaan Dan Perancangan Desa Wisata Di Desa Nainggolan
}

\author{
Author $\quad$ : Suci Ananda Puteri Tarigan dan B O Y Marpaung \\ DOI $\quad: 10.32734 /$ ee.v3i1.873 \\ Electronic ISSN $\quad: 2654-704 \mathrm{X}$ \\ Print ISSN : $2654-7031$
}

Volume 3 Issue 1 - 2020 TALENTA Conference Series: Energy \& Engineering (EE)

This work is licensed under a Creative Commons Attribution-NoDerivatives 4.0 International License.

Published under licence by TALENTA Publisher, Universitas Sumatera Utara 


\title{
jibli - TALENTA Conference Series
}

Available online at https://talentaconfseries.usu.ac.id/ee

\section{Pengaruh Sosial Budaya Terhadap Perencanaan Dan Perancangan Desa Wisata Di Desa Nainggolan}

\author{
Socio-Cultural Effects of Tourism Village Planning and Design in the Village \\ Nainggolan
}

\author{
Suci Ananda Puteri Tarigan¹, B O Y Marpaung ${ }^{2}$ \\ ${ }^{1,2}$ Program Studi Magister Teknik Arsitektur Fakultas Teknik Universitas Sumatera Utara, Medan, Indonesia
}

${ }^{1}$ sucyananda95@gmail.com, ${ }^{2}$ beny.marpaung@usu.ac.id

\begin{abstract}
Abstrak
Penelitian tentang pengaruh sosial budaya terhadap perencanaan dan perancangan desa wisata ini menggunakan metode deskriptif kualitatif. Penelitian ini dilakukan di Desa Nainggolan, kecamatan Nainggolan Kabupaten Samosir. Berdasarkan hasil survey yang telah dilakukan di lokasi penelitian, ditemukan bahwa kegiatan sosial budaya yang terdapat pada desa Nainggolan berpotensi dilakukan perencanaan untuk dirancang sebagai desa wisata. Adapun jika desa Nainggolan telah diwujudkan menjadi desa wisata, maka akan meningkatkan pariwisata dan perekonomian pada desa Nainggolan. Adapun sosial budaya yang terbentuk pada desa Naingolan tidak lepas dari kontribusi dan partisipasi masyarakat Nainggolan. Keterlibatan masyarakat Nainggolan pada proses perencanaan dan perancangan desa Nainggolanakan memberikan penagaruh yang signifikan pada kemanjaun desa. Selain itu, agar desa Nainggolan dapat berhasil diwujudkan menjadi desa wisata, desa harus memilki keunikan. Pengaruh sosial budaya dalam terbentukannya keunikan dan kekhasan di desa Nainggolan juga berperan penting, sehingga sosial budaya pada desa Nainggolan harus tetap dijaga dan dilestarikan. Selain menjaga dan melestarikan sosial budaya yang dimilki pada desa Nainggolan,ketersediaan fasilitasfasilitas yang mendukung bagi wisatawan juga sangat berperan dalam terbentuknya desa wisata.berdasarkan hal tersebut, peran pemerintah dan stakeholder sangat dibutuhkan dalam menyediakan fasilitas-fasilitas yang mumpuni namun tetap menjaga sosial budaya pada desa Nainggolan serta tidak merugikan masyarakat lokal desa Nainggolan sehingga keberhasilan desa Nainggolan.
\end{abstract}

Kata kunci: Sosial, Budaya, Pariwisata.

\begin{abstract}
Research on the influence of socio-culture on the planning and design of this tourist village using descriptive qualitative methods. This research was conducted in Nainggolan Village, Nainggolan District, Samosir Regency. Based on the results of a survey conducted at the study site, it was found that the socio-cultural activities contained in the Nainggolan village have the potential to be planned to be designed as a tourist village. Meanwhile, if the Nainggolan village has been transformed into a tourism village, it will increase tourism and the economy in the Nainggolan village. The social culture formed in the village of Naingolan cannot be separated from the contribution and participation of the Nainggolan community. The involvement of the Nainggolan community in the planning and design process of the Nainggolanakan village has a significant influence on the progress of the village. In addition, for the Nainggolan village to be successfully transformed into a tourist village, the village must have its uniqueness. The influence of socio-culture in the formation of uniqueness and uniqueness in the village of Nainggolan also plays an important role, so the socio-culture in the village of Nainggolan must be maintained and preserved. In addition to maintaining and preserving the socio-culture that is owned in the village of Nainggolan, the availability of supporting facilities for tourists also plays an important role in the formation of a tourism village. in the Nainggolan village and did not harm the local community of Nainggolan village so that the success of the Nainggolan village.
\end{abstract}

Keywords: Social, Culture, Tourism.

(C) 2020 The Authors. Published by TALENTA Publisher Universitas Sumatera Utara

Selection and peer-review under responsibility of Seminar Nasional Kearifan Lokal V 2020

p-ISSN: 2654-7031, e-ISSN: 2654-704X, DOI: 10.32734/ee.v3i1.873 


\section{Pendahuluan}

Meningkatnya kunjungan wisatawan ke Indonesia, berbanding lurus terhadap meningkatnya permintaan produk wisata di Indonesia. Menurut data statistik, kunjungan wisatawan mancanegara ke Indonesia pada tahun2019 yan berjumlah 1.354.396 kunjungan atau mengalami peningkatan sebesar 4,86\% dibandingkan pada periode yang sama di bulan Oktober tahun 2018 yang berjumlah 1.291 .605 kunjungan [1] Peningkatan tersebut juga memberi dampak terhadap permintaan produk pariwisata di provinsi Sumatera Utara. Berdasarkan data statistik, kunjungan wisatawan mancanegara ke Sumatera Utara pada Oktober 2019 yang berjumlah 22.556 atau mengalami kenaikan sebesar 39,84\% dibandingkan pada periode yang sama pada tahun 2018 yang berjumlah 1.291.605 kunjungan [2]. Fenomena ini dilihat pemerintah daerah dan stake holder sebagai peluang untuk meningkatkan sektor pariwisata.

Menurut United Nations world tourism Organization tahun 2008. Pariwisata merupakan fenomena sosial, budaya yang mensyaratkan perpindahan orang ke negara atau tempat di luar lingkungan biasanya untuk keperluan pribadi atau bisnis / profesional. Berdasarkan tingginya kunjungan wisatawan mancanegara yang berkunjung ke Indonesia dan menerapkan aspek sosial budaya sebagai daya tarik, maka wisata dengan kearifan lokal merupakan peluang yang menjanjikan. Salah satu bentuk peluang pariwisata yang menerapkan kearifan lokal sebagai daya tarik untuk meningkatkan sektor pariwisata adalah desa wisata.

Desa Nainggolan merupakan salah satu desa yang menjadi tujuan wisata di kabupaten Samosir. Menurut Badan Pusat Statistik Pulau Samosir tahun 2018, Desa Nainggolan termasuk desa Swakarya, yaitu desa yang telah dapat memenuhi kebutuhannya sendiri dan dapat mulai memasarkan produksinta kedaerah-daerah lain dalam hal ini berupa hasil pertanian dan hasil ternak.

\section{Tinjauan Pustaka}

\subsection{Pengertian Pariwisata}

Pariwisata merupakan suatu perjalanan yang dilakukan seorang individu yang bersifat sementara untuk meninggalkan tempat asalnya menuju tempat lain yang memiliki atmosfer berbeda dengan tempat asalnya dengan tujuan untuk rekreasi [3].

\subsection{Komponen Pariwisata}

Desa Nainggolan yang akan dikembankan menjadi desa wisata harus mampu memfasilitasi kebutuhan wisatawan akan rekreasi dan kebutuhan lainnya. Adapun menurut Suwena (2010), bahwasanya terdapat dua faktor yang berperan sebagai komponen pariwisataterkait untuk mendukung dan memfasilitasi pengembangan desa wisata, yaitu komponen penyedia (supply) dan permintaan (demand). Adapun komponen penyedia mencakup segalaSesuatu yang akan ditawarkan kepada wisatwan, yaitu infrastruktur, atraksi wisata, fasilitas pendukung, dan sebagainya. Sedankan untuk komponen permintaan mencakup segala Sesutu yang berkaitan dengan permintaan pariwisata yaitu subjek ataupun pelaku yang terlibat dalam pariwisata tersebut misalnya, wisatawan danmasyarakat.

\subsection{Pengertian Desa Wisata}

Menurut Haryanto (2013), desa wisata merupakan implementasi dari pembangunan pariwisata bergantung kepada masayarakat lokal dan bersifat berkelanjutan. Implementasi dari pembangunan pariwisata bergantung kepada masayarakat lokal dan bersifat berkelanjutanbahwa aspek-aspek yang paling menonjol apabila kawasan wisata tersebut merupakan pariwisata bekelanjutan adalah (1) aspek ekonomi, (2) aspek lingkungan, dan (3) aspek sosial budaya. 


\subsection{Komponen Desa Wisata}

Dalam melakukan perencanaan dan perancangan desa wisata, terdapat komponen yang Yang berperan untuk mendukung terwujudnya desa wisata. Menurut Gumelar (2010), komponen dalam terbentuknya desa wisata yaitu adanya keunikan pada desa tersebut dan lokasi desa wisata yang memilki potensi alam yang luarbiasa. Selain itu, dalam proses perencanaan dan perancangan desa wisata peran pelaku pariwisata memiliki kontribusi besar untuk mewujudkan desa wisata. Adapun pelaku yang berkontribusi besar dalam proses pengembangan desa wisata adalah partisipasi masyarakat lokal [4].

Dalam melakukan penilaian dalam sektor pariwisata terhadap cara hidup serta aktivitas sehari-hari yang dilakukan oleh masyarakat lokal, akan sulit untuk dilakukan terutama dalam segi metodologinya (Pitana dan Gayatri, 2005). Jika sosial budaya dikaitkan dengan pengembangan desa wisata, maka dalam menanalisa dampak maupun peran sosial budaya pada desa wisata tidak akan mudah untuk dilakukan karena desawisata yang dilakukan penelitian sudah pasti sudah terkena dampak modernisasi sehingganilai-nilai sosialbudaya yang otentik pada desa tersebut telah berkurang. Selain itu, Pitana dan Gayatri (2005) juga menambahkan, bahwasanya akan terjadi perubahan sosial budaya yang terjadi yang diakibatkan kunjungan wisatawan ke desa wisata,yaitu:

- Perubahan yang terjadi akibat pengaruh ekternal. Biasanya perubahan ini terjadi karean pengaruh eksternal yang cenderung lebih kuat sehingga mmepngaruhi nilai sosial budaya yang dimilikidesa.

- Perubahan yang bersifat destruktif bagi sosial-budaya masyarakatdesa.

- Perubahan yang akan berdampak terhadap tenggelamnya identitas sosial-budaya lokal akibat pengaaruh dari kemjuanteknologi.

Berdasarkan dampak perubahan yang terjadi akibat kunjungan wisata, maka identitas desa yang terbentuk dari adanya nilai-nilai sosial budaya pada suatu desa haruslah menjadi orientasi bagi masyarakat desa Nainggolan serta menjaga dan melestarikan nilai-nilai sosial budaya pada desa Nainggolan yang berpotensi dilakukan pengembangan menjadi desawisata.

\section{Metode Penelitian}

Penelitian ini menggunakan metode deskriptif kualitatif yang bertujuan untuk memaparkan dan mendeskripsikan masalah berdasarkan fenomena faktual yang ada di lapangan [5]. Adapun pada penelitian ini, yang menjadi subjek penelitian adalah tempat pelaku dan aktivitas [6]. Adapun sistematika teknik pengumpulan data pada penelitian di Desa Nainggolan adalah dengan melakukan observasi, wawancara dan dokumentasi.

\section{Hasil dan Pembahasan}

\subsection{Kawasan Kampung}

Desa Nainggolan adalah sebuah desa yang terletak di kecamatan Nainggolan, kabupaten Samosir, Provinsi Sumatera Utara, Indonesia. Desa yang memiliki luas area sebesar 5,30 km2 ini terletak di bagian tenggara Pulau Samosir, dengan Desa parhusip III sebagai batas di sebelah utara, desa Sibonor Ompu Ratus dan desa Sinaga Uruk Pandiangan disebelah barat. Kemudian pada bagian selatan, Desa Nainggolan berbatasan dengan Danau Toba, dan bagian Timur berbatasan dengan desa Siruma Hombar dan desa Sipinang Lumban Siantar. Dapat dilihat pada gambar dibawah, Danau Toba mengelilingi 3/4 dari desa Nainggolan hingga menjadikan desa ini memiliki potensi alamyang sangat baik untuk dikembangkan menjadi desa wisata (Gambar3.1). 


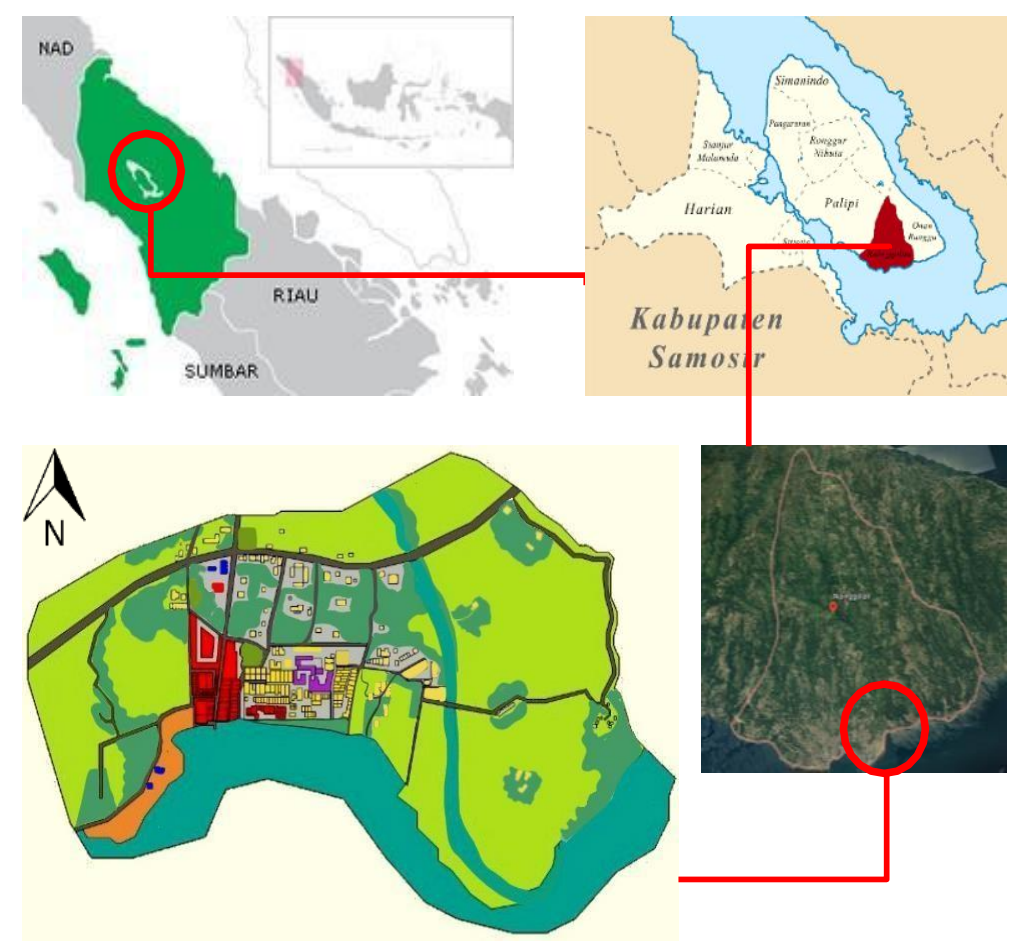

Gambar 3.1 Lokasi Kajian, Desa Nainggolan

Menurut Badan Pusat Statistik Pulau Samosir tahun 2018, Desa Nainggolan adalah termasuk desa Swakarya, yaitu desa yang telah dapat memenuhi kebutuhannya sendiri dan dapat mulai memasarkan produksinta kedaerah-daerah lain dalam hal ini berupa hasil pertanian dan hasil ternak. Pada desa Nainggolan juga telah terdapat diversifikasi mata pencaharian, serta masyarakat desanya terbuka dan dapat menerima pengaruh dari luar sehingga menyebabkan pola pikir masyarakat mulai berubah, adat istiadat tidak lagi terlalu mengikat, sarana dan prasarana juga telah lebih baik sehingga tidak lagi terisolir walaupun letaknya jauh dari pusat perekonomian. Keterbukaan masyarakat serta sarana prasarana yang tergolong cukup baik dapat dikembangkan dan dijadikan faktor pendukung pengembangan sektor pariwista pada desa Nainggolan.

\section{Aspek Sosial}

Pada desa Nainggolan mata pencaharian mayoritas masyarakatnya adalah bertani dan nelayan. Selain padi, vegetasi yang banyak dijumpai di desa Nainggolan adalah Jagung dan Kopi. Selain itu terdapat pula aktivitas perdagangan pada desa ini yang biasa disebut Onan (pasar) yang diadakan seminggu sekali setiap hari senin. Onan ini biasa mulai beroperasi pukul 08.30 WIB, namun para pedagang mulai membuka kios dan menyusun dagangannya mulai dari jam 08.00 WIB. Pada Onan ini diperjual-belikan berbagai macam barang kebutuhan pokok dan hasil alam seperti beraneka sayuran, buah-buahan, aneka ternak dan tentunya ikan mas, ikan khas dari Danau Toba. Pada area dekat dermaga yang biasa dijadikan Onan, penataan dalam keadaan tidak teratur. Tidak ada jalur pedestrian dan pengaturan area parkir yang sesuai, menyebabkan ketidaknyamanan pada saat berbelanja, sehingga perlu dilakukan penataan agar memudahkan aktifitas jual-beli serta dapat menjadi potensi visual bagi wisatawan. Desa Nainggolan yang telah menjadi desa terbuka, banyak pula melakukan aktivitas perdagangan antar-pulau. Aktivitas perdagangan antar pulau ini diakomodir dengan menggunakan Kapal Motor Penumpang (KMP) dengan rute Nainggolan-Muara Setiap hari kamis pukul 08.00 WIB, Nainggolan-Bakara setiap hari rabu pukul 12.00 WIB (Gambar3.2). 


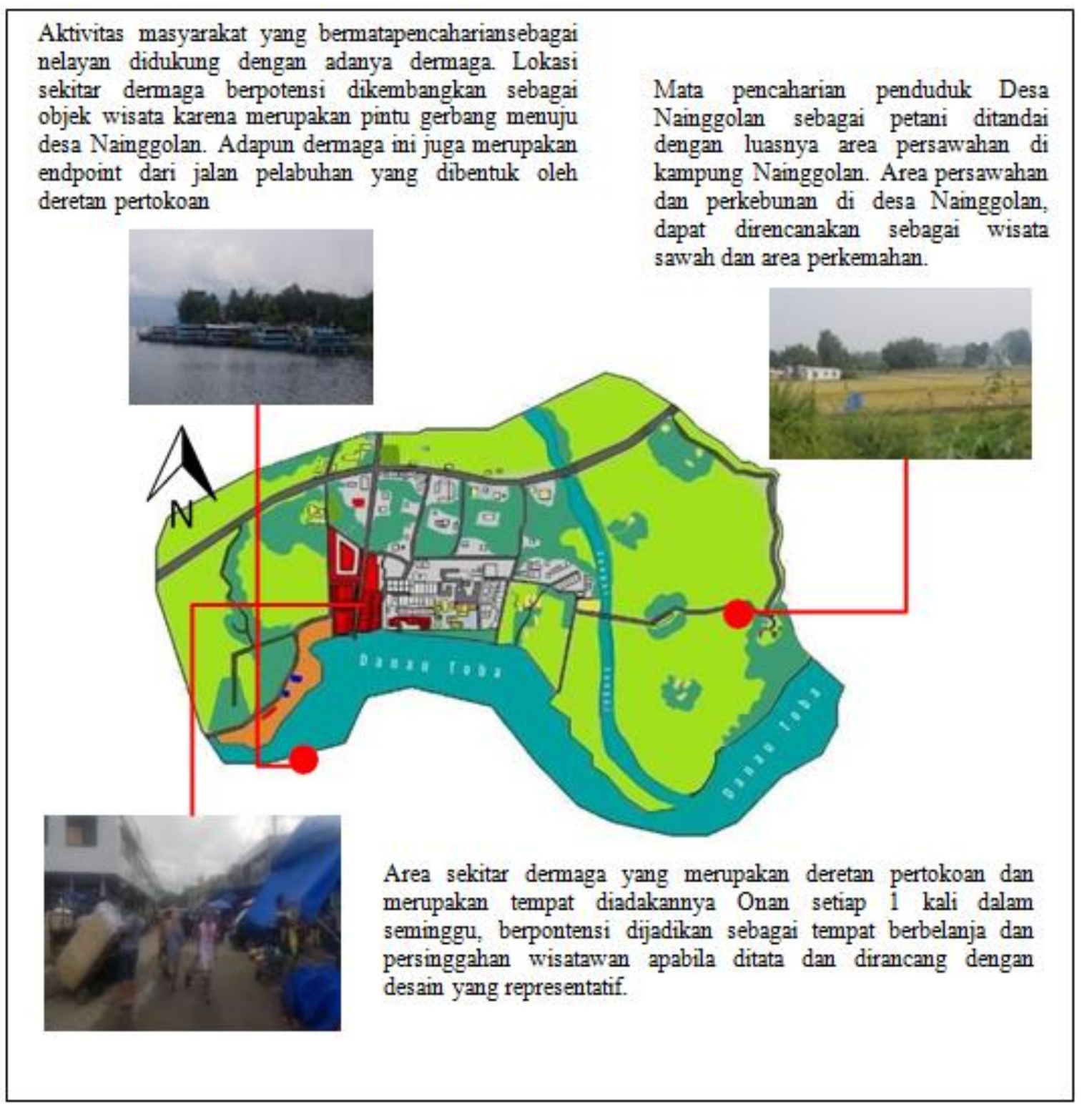

Gambar 3.2 Kajian Aspek Sosial Desa Nainggolan 


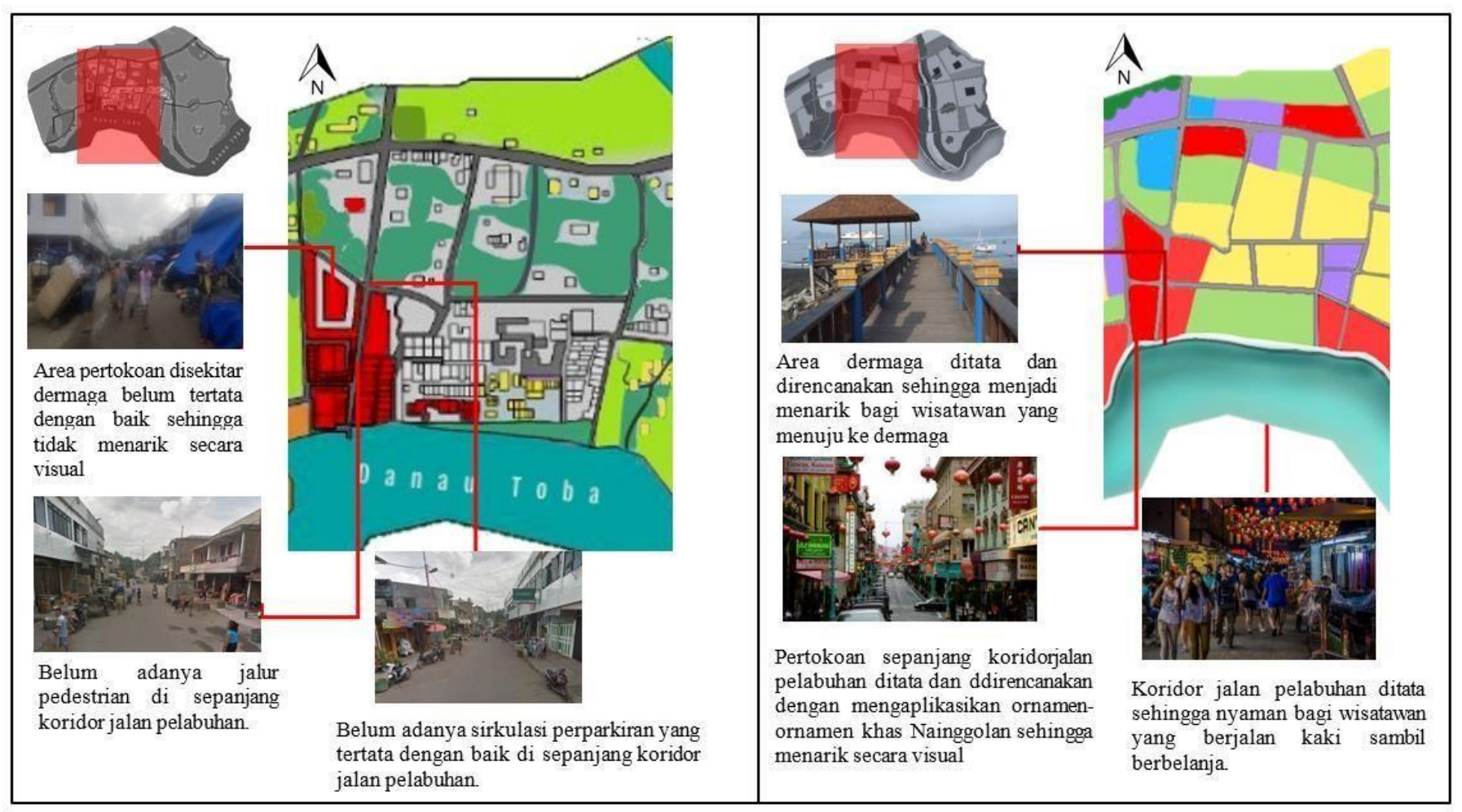

Gambar 3.3 Kajian Masalah dan Solusi Aspek Sosial Desa Nainggolan

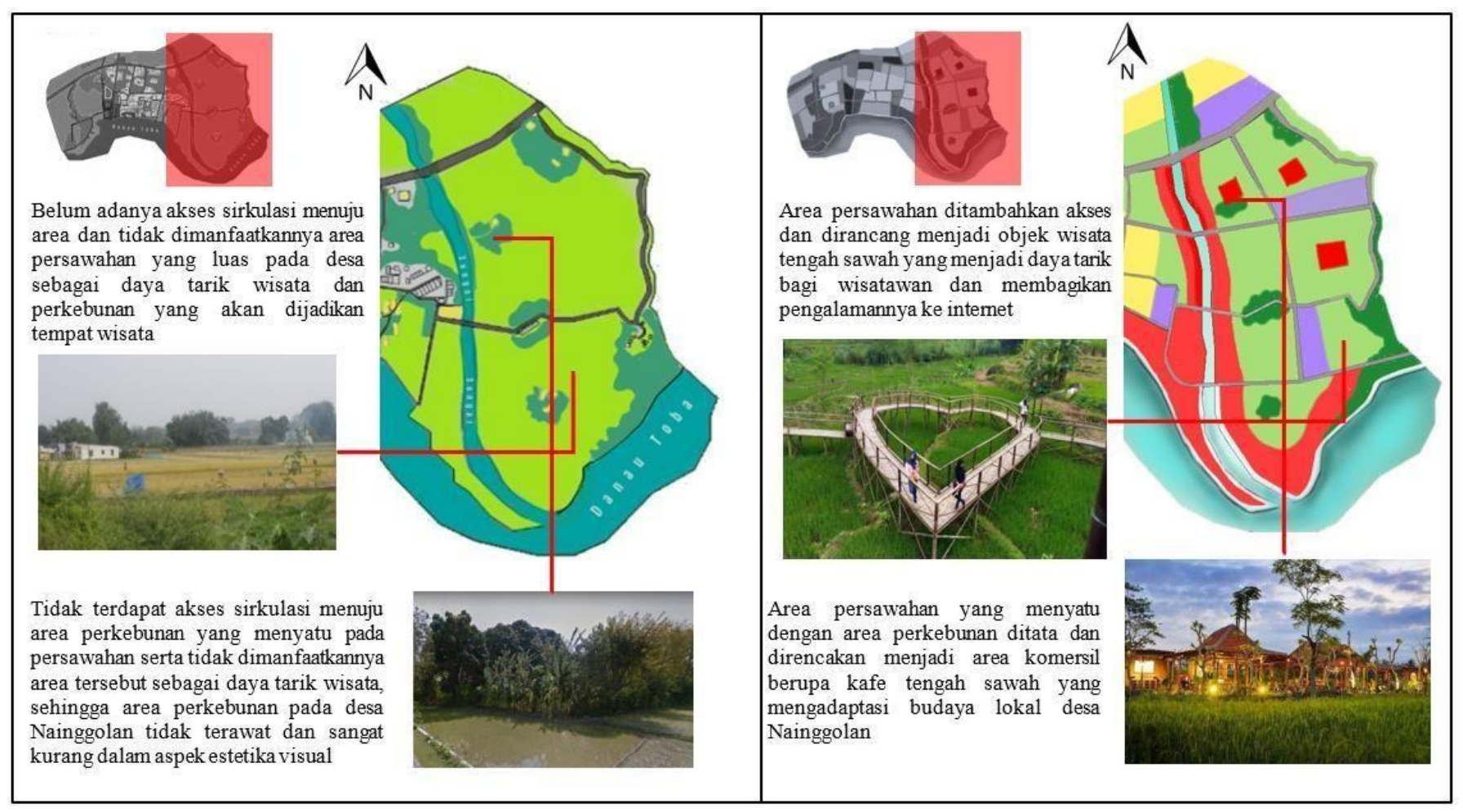

Gambar 3.4 Kajian Masalah dan Solusi Aspek Sosial pada Area Persawahan Desa Nainggolan 


\section{Budaya}

Pantai Pasir Putih Pandua yang merupakan area tepi air Desa nainggolan adalah area yang mulai dibenahi dan dibangun sehubungan dengan kepentingan kepariwisataan. Pantai ini dijadikan tempat dilangsungkannya Festival tahunan seperti Festival Paskah Raya dan Festival dalam rangka merayakan hari kemerdekaan Republik Indonesia setiap tanggal 17 Agustus, dan Festival kapal hias dengan rute dari perbatasan Onan Runggu ke Nainggolan. Area terbuka yang biasa dijadikan tempat dilangsungkannya Festival Paskah Raya dan Festival 17 Agustus setiap tahun, dapat dimaksimalkan potensinya dengan penataan ulang. Area ini dapat dijadikan tempat diadakannya pertunjukan budaya yang diselenggarakan secara berkala, yang terintegrasi dengan danau dan tempat rekreasi air.

Tradisi pada masyarakat desa Nainggolan walaupun tidak lagi terlalu mengikat tetapi bagi masyarakat yang ingin melakukan upacara tradisi dan adat istiadat sukacita, dilakukan di Sopo Godang HKBP yang terletak tepat didekat pintu masuk desa dan bersebelahan dengan gereja HKBP desa Nainggolan.Pada desa nainggolan masih terdapat kekhasan budaya batak, hal ini dapat dilihat dari masih banyaknya rumah-rumah tradisional batak dan pemakaman dengan ornamen khas batak.

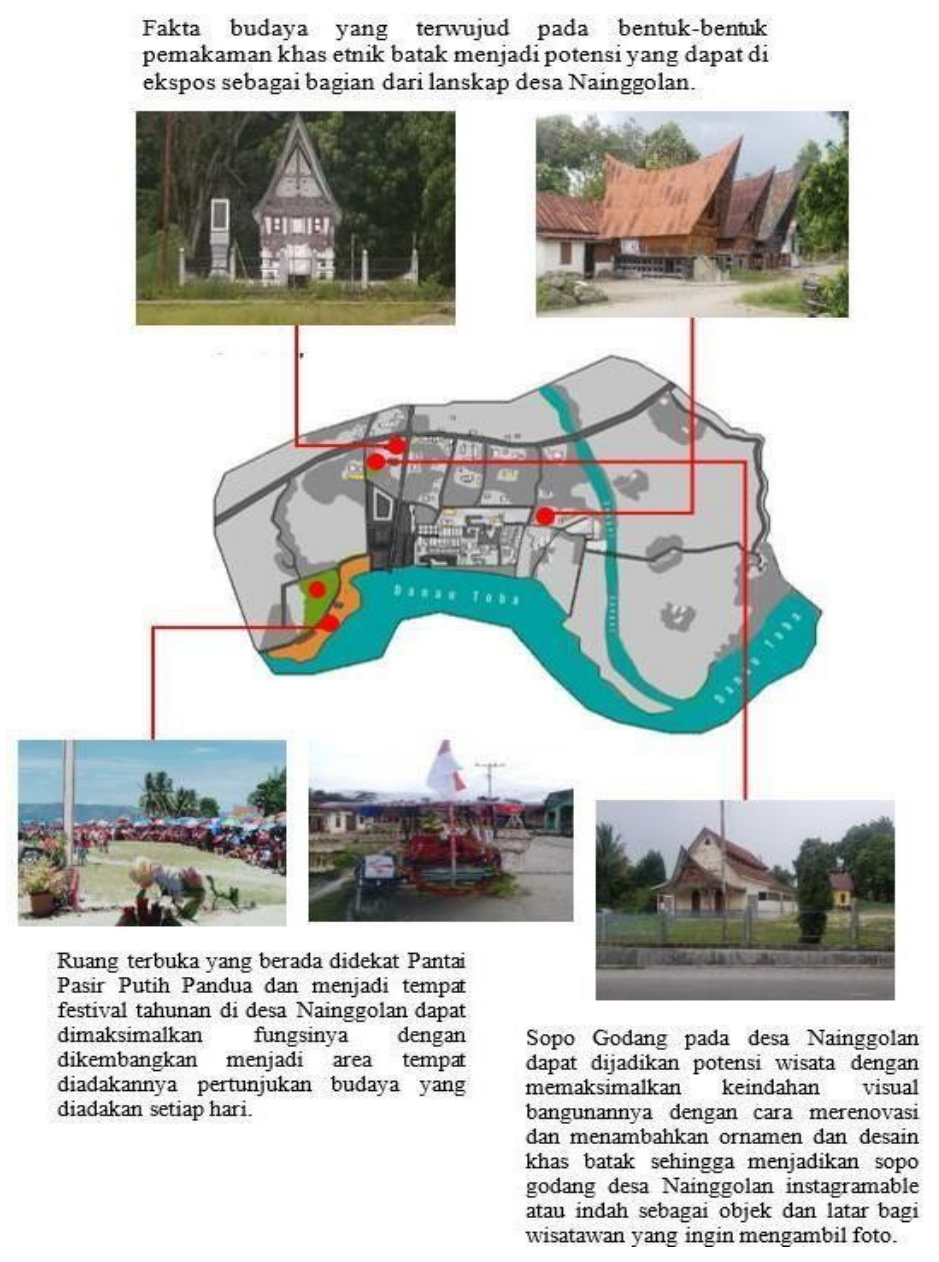

Gambar 3.5 Kajian Aspek Budaya Desa Nainggolan 


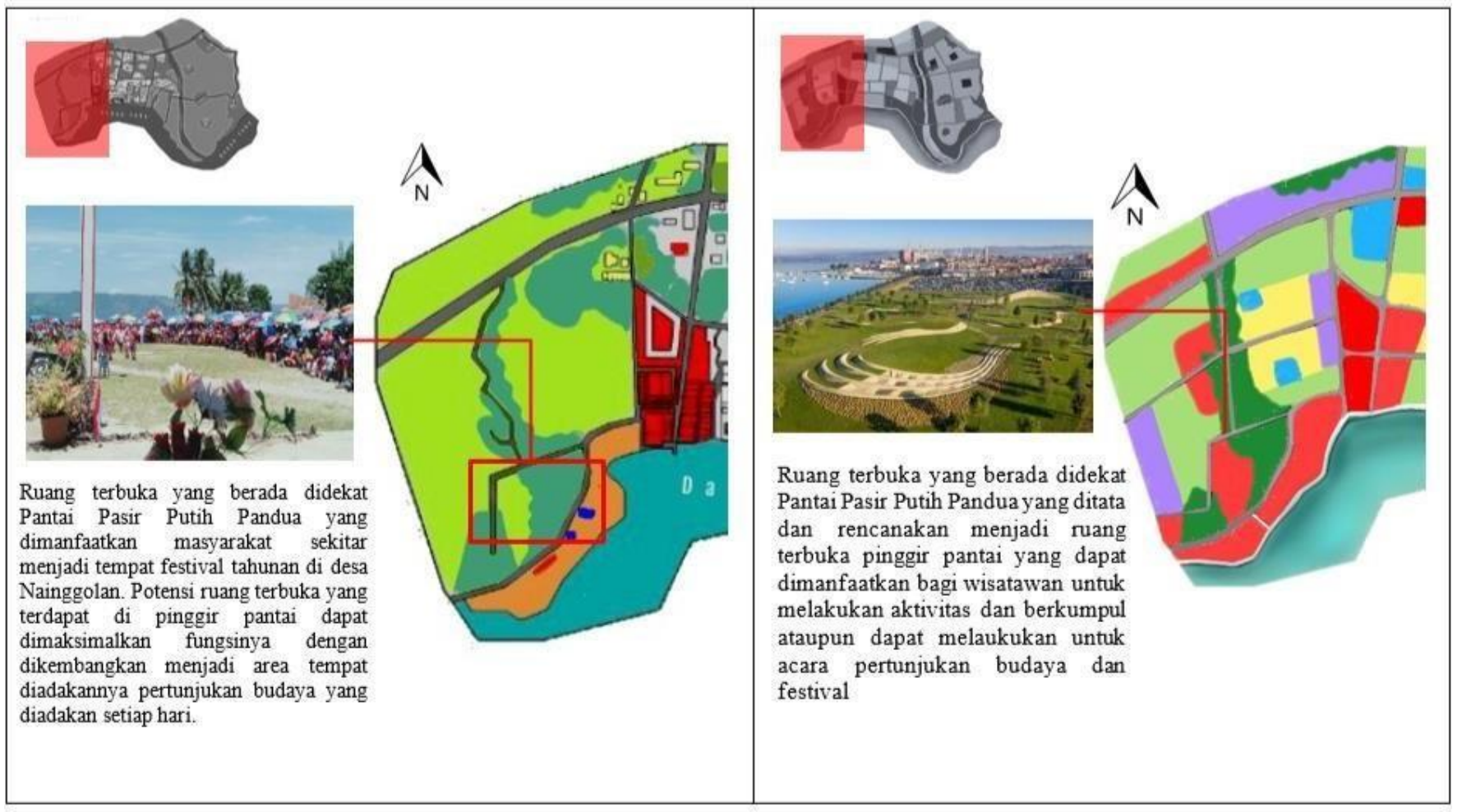

Gambar 3.6 Kajian Masalah dan Solusi Aspek Budaya pada Area Pinggir Pantai Desa Nainggolan

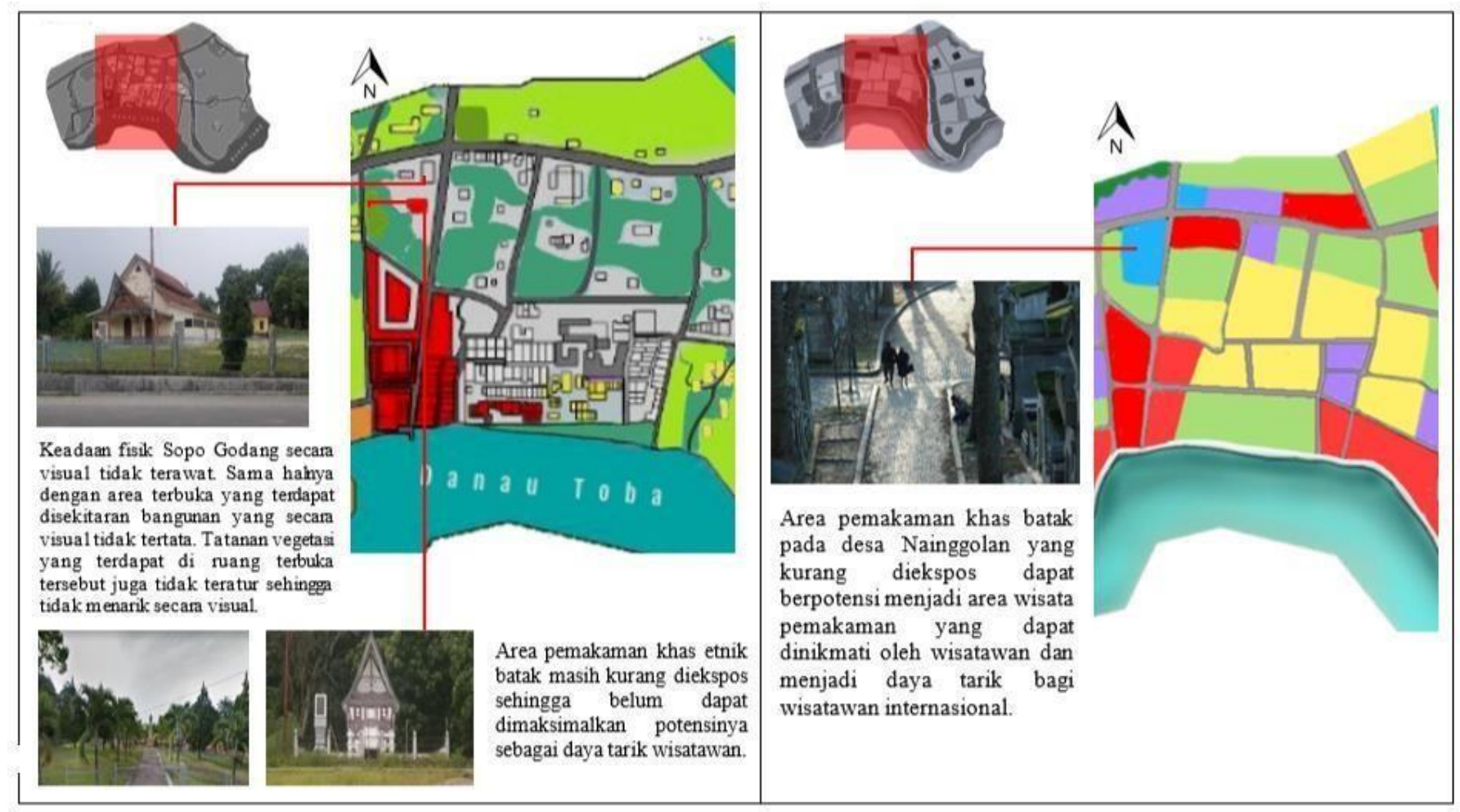

Gambar 3.7 Kajian Masalah dan Solusi Aspek Budaya pada Sopo Godang dan Area pemakaman Desa 


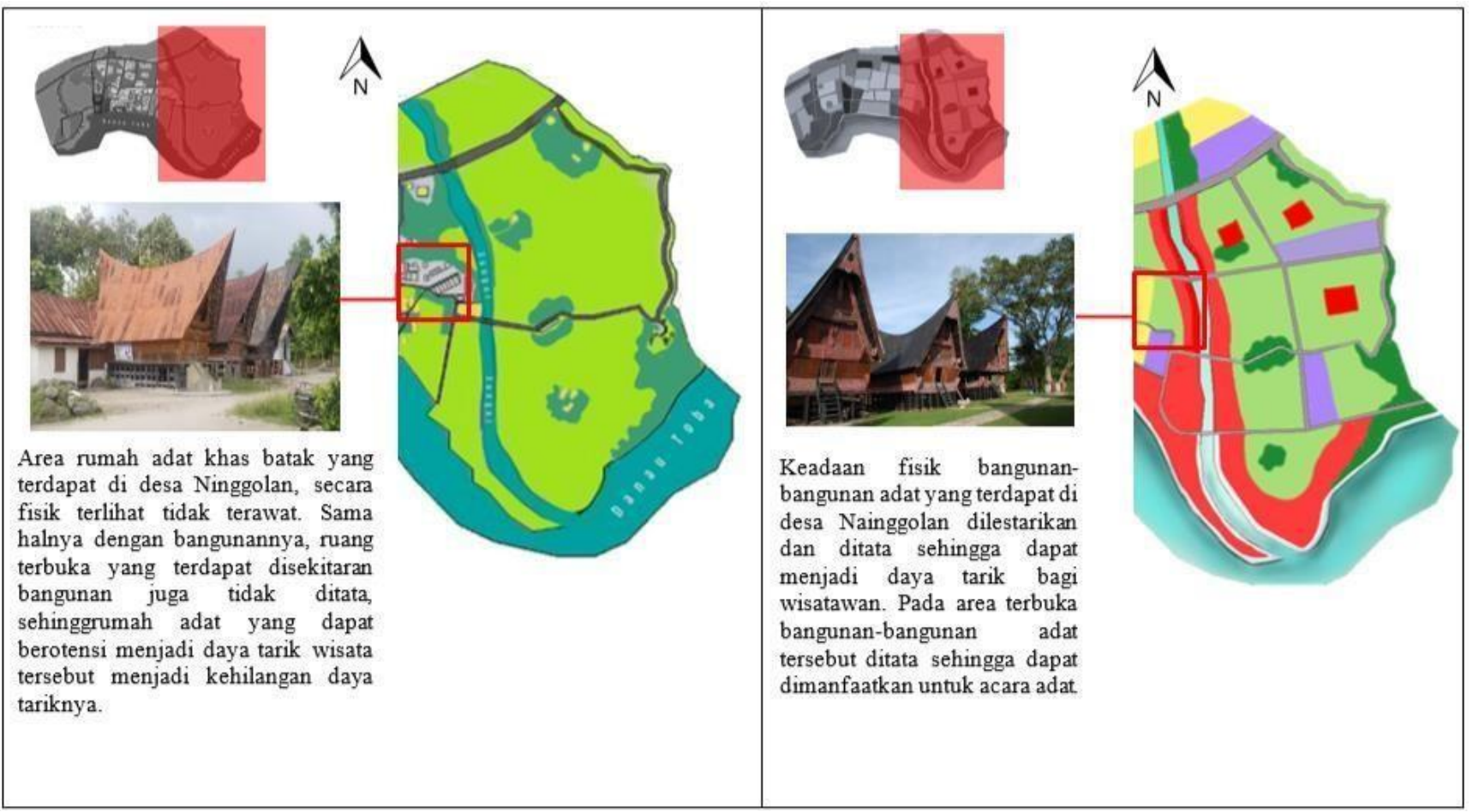

Gambar 3.8 Kajian Masalah dan Solusi Aspek Budaya pada Sopo Godang dan Area pemakaman Desa

\section{Referensi}

[1] Gumelar S. Sastrayuda (2010), - Konsep Pengembangan Kawasan Desa Wisatall (Handout Mata Kuliah Consept Resort and Leisure, Strategi Pengembangan dan Pengelolaan Resort andLeisurell

[2] Haryanto, J, T., 2013 Implementasi Nilai-Nilai Budaya, Sosial, Dan Lingkungan Pengembangan Desa Wisata Di Provinsi Yogyakarta

[3] Kementerian Kebudayaan dan Pariwisata Indonesia, 2004, Rencana Strategis Pembangunan Kebudayaandan Kepariwisataan Nasional Tahun 2005- 2009: Ringkasan Eksekutif. Jakarta: Kementerian Kebudayaan dan PariwisataIndonesia.

[4] I Gde Pitana., \& Putu G, Gayatri. (2005). Sosiologi Pariwisata Yogyakarta : CV Andi Offset

[5] Prasiasa, Putu Oka (2012). Destinasi pariwisata, berbasis masyarakat, Jakarta : SalembaEmpat

[6] Sinaga, Supriono. 2010. Potensi dan Pengembangan Objek Wisata Di Kabupaten Tapanuli Tengah. Kertas Karya. Program DIII Pariwisata. Universitas SumateraUtara.

[7] Suwena, I Ketut. 2010. "FormatPariwisataMasa Depan” dalam Pariwisata Berkelanjutan dalam Pusaran Krisis Global, Denpasar : Udayana UniversityPress 